\title{
RESTAURAÇÃO FLORESTAL VISANDO À CONSERVAÇÃO DE RECURSOS HÍDRICOS POR MEIO DA COMBINAÇÃO LINEAR PONDERADA
}

\author{
Anderson Antonio da Conceição Sartori ${ }^{1}$, Fábio Ávila Nossack ${ }^{2}$, Ramon Felipe Bicudo da Silva ${ }^{3}$, \\ Célia Regina Lopes Zimback ${ }^{4}$
}

${ }^{1}$ Eng. Agrônomo, M.Sc., Depto. Recursos Naturais - Ciência do Solo, GEPAG, FCA/UNESP, Botucatu, SP, Brasil - sartori80@ gmail.com ${ }^{2}$ Eng. Florestal, Depto. Recursos Naturais - Ciência do Solo, FCA/UNESP, Botucatu, SP, Brasil - fanossack@ yahoo.com.br ${ }^{3}$ Biólogo, M.Sc., Depto. Recursos Naturais - Ciência do Solo, FCA/UNESP, Botucatu, SP, Brasil - ramonbicudo@ yahoo.com.br ${ }^{4}$ Eng $^{\mathrm{a}}$ Agrônoma, Dra ${ }^{\mathrm{a}}$, Depto. Recursos Naturais - Ciência do Solo, FCA/UNESP, Botucatu, SP, Brasil - czimback@ gmail.com

Recebido para publicação: 08/02/2011 - Aceito para publicação: 04/10/2011

\begin{abstract}
Resumo
Este estudo teve como objetivo avaliar o emprego da Avaliação Multicritérios em ambiente SIG, especificamente por meio do método Combinação Linear Ponderada, na geração de mapa de área prioritária à restauração florestal, na parte inicial da bacia do rio Pardo, SP, visando à conservação de recursos hídricos. Na definição dos critérios e restrições, empregou-se a Técnica Participativa. Foram selecionados os seguintes fatores: proximidade da rede hidrográfica, proximidade da cobertura florestal, declividade e erodibilidade do solo. Para calcular o peso para cada fator, foi utilizado o processo de tomada de decisão, conhecido como Análise Hierárquica Analítica. Esse método emprega uma comparação pareada entre fatores para determinar a importância relativa de cada um deles. Pela Combinação Linear Ponderada, as áreas de prioridade muito alta apresentam uma distribuição espacial mais restrita, com uma concentração aparente ao redor dos corpos d'água, delineando uma área-tampão (buffer) para a rede hidrográfica. $\mathrm{O}$ fator proximidade da rede hidrográfica, além de possibilitar a conexão florestal, colaborou, juntamente com o fator proximidade da cobertura florestal, para que houvesse a definição de grande parte das áreas com maior prioridade em regiões da bacia, que concentram as maiores áreas de floresta nativa e áreas ripárias ao longo da hidrografia.
\end{abstract}

Palavras-chave: Recomposição florestal; áreas prioritárias; SIG.

\begin{abstract}
Forest restoration aiming at the conservation of water resources by Weighted Linear Combination. This study evaluated using of Multicriteria Evaluation in a GIS, specifically by Weighted Linear Combination Method for generation of map of priority areas for forest restoration in the initial part of River Pardo Basin, SP, in order to water resources conservation. Aiming to define criteria and restrictions it was used Participatory Techniques, and the following factors had been selected: proximity of the hydrographic network, proximity of forest cover, slope and erodibility of soil. To calculate the weight to each factor it was used the decision-making process, known as Analytic Hierarchy Analysis, this method consists of a paired comparison of factors to determine the relative importance of each. According to Weighted Linear Combination, the very high priority areas have a more limited spatial distribution, with an apparent concentration around the water bodies, outlining a buffer to the river system. The proximity factor of the hydrographic network, and enables the connection forestry, contributed, along with the factor of proximity to forest cover, so there would be the definition of most of the areas with the highest priority in the basin, which concentrate the largest areas of forest and native riparian areas along the hydrographic.
\end{abstract}

Keywords: Multicriteria evaluation; priority areas; GIS.

\section{INTRODUÇÃO}

A sub-bacia do Rio Pardo representa muito bem a situação de grande parte do território brasileiro originalmente coberto pela Mata Atlântica, onde a fragmentação florestal é um dos resultados do processo 
desordenado de uso e ocupação do solo, especialmente em paisagens intensamente cultivadas (VALENTE, 2005).

Assim, depreende-se que a oferta natural de água, em quantidade e qualidade adequadas, depende, entre outros fatores, de um planejamento adequado do uso e cobertura do solo. $\mathrm{O}$ reflorestamento dirigido em bacias hidrográficas, notadamente por meio de ações de restauração florestal, tem sido apontado como uma das soluções mais factíveis e baratas para a questão da produção de água de boa qualidade para o uso humano (VETTORAZZI, 2006). O problema é que, mesmo sendo uma solução das mais baratas, a restauração apresenta um custo elevado, exigindo um planejamento cuidadoso que aponte áreas prioritárias para o investimento de recursos em reflorestamento.

Existem diferentes abordagens interessantes para serem utilizadas na determinação dessas áreas prioritárias, como o emprego de modelos hidrológicos, índices de produção de sedimentos etc., mas, de qualquer forma, a exigência da explicitação da distribuição espacial das áreas a serem restauradas torna imprescindível, nessa tarefa, o uso dos Sistemas de Informações Geográficas (SIGs), dada a sua capacidade de análise de dados de natureza espacial (VETTORAZZI, 2006).

Em muitas das aplicações de SIG na área de análise ambiental, é comum o envolvimento de múltiplos critérios para se atender a um ou mais objetivos. É a denominada Avaliação Multicritérios (AMC). Problemas de decisão espacial normalmente envolvem um grande conjunto de alternativas viáveis e múltiplas. As alternativas são frequentemente avaliadas por um certo número de indivíduos: os decisores políticos, gestores, agentes, pesquisadores, grupos de interesse (MALCZEWSKI, 2006).

Os dois distintos domínios de pesquisa, SIG e AMC, podem beneficiar-se um do outro (CHAKHAR; MARTEL, 2003; MALCZEWSKI, 1999). Por um lado, técnicas de SIG e procedimentos de multicritérios têm um papel importante a desempenhar na análise de problemas de decisão. Na verdade, SIG é frequentemente reconhecido como um sistema de apoio à decisão, envolvendo a integração de dados espacialmente referenciados em um ambiente de resolução de problemas. Por outro lado, AMC fornece um rico conjunto de técnicas e procedimentos para estruturar problemas de decisão, projetar, avaliar e priorizar decisões alternativas (COWEN, 1988).

Os conceitos dos tomadores de decisão são expressos por critérios que podem ser medidos e avaliados e que constituem a base do processo de tomada de decisão (EASTMAN, 2001). Para esse autor, o critério é a evidência sobre a qual um indivíduo pode ser designado a um conjunto de decisão. Os critérios podem ser de dois tipos (fatores e restrições) e podem referir-se tanto a atributos do indivíduo como ao conjunto todo de decisão.

Para a integração dos diferentes fatores, com base na abordagem multicriterial, vários métodos vêm sendo utilizados, segundo Malczewski (2004). Desses métodos de Avaliação Multicritérios (AMC) que têm sido implementados em ambiente SIG, destacam-se o método Booleano, a Combinação Linear Ponderada (CLP) e suas variantes, o Método do Ponto Ideal, a Análise de Concordância e o Processo Hierárquico Analítico. Entre esses métodos, a Combinação Linear Ponderada e o Booleano são os mais robustos e os empregados com mais frequência.

Para a definição de áreas sensíveis, prioritárias ou de risco, o método da Combinação Linear Ponderada vem sendo empregado em diversos campos da pesquisa. Zhu e Dale (2001) desenvolveram um programa com base nesse método e o empregaram para a determinação de áreas prioritárias para o manejo sustentável, tendo em vista a qualidade da água de uma bacia hidrográfica na região centro-oeste da Austrália. Donha et al. (2006) utilizaram o programa para determinar a fragilidade ambiental de uma área no município de Pinhais, Região Metropolitana de Curitiba (PR). Calijuri et al. (2007) propuseram uma metodologia para geração da carta de fragilidade ambiental utilizando lógica Fuzzy e Combinação Linear Ponderada.

Ribeiro (2010) analisou quais fatores do meio físico natural ou modificado influenciam a capacidade de infiltração das águas da bacia hidrográfica Vargens de Caldas, de forma a definir áreas potencialmente favoráveis à infiltração, gerando como produto um mapa da capacidade de infiltração da bacia, através da Combinação Linear Ponderada.

Sartori (2010), objetivando definir as áreas prioritárias para restauração florestal e garantir a conectividade dos fragmentos florestais, utilizou a abordagem multicriterial, em ambiente SIG, com o Método da Combinação Linear Ponderada, para combinação dos fatores (características da paisagem) importantes ao objetivo do trabalho. 
A utilização da abordagem multicriterial como forma de planejamento da restauração florestal tem mitigado a supressão de áreas florestais e sua substituição por outros tipos de uso do solo, podendo contribuir, de forma significativa, para os processos de geração, transporte e deposição de sedimentos nos canais de drenagem. As florestas de encosta protegem a superfície do solo do início do processo erosivo, promovem a infiltração da água no solo e funcionam como barreiras ao transporte dos sedimentos. Ao redor das nascentes, elas têm importante função de proteção, principalmente contra compactação e o assoreamento por práticas agrícolas inadequadas (VETTORAZZI, 2006).

Harrington (1999) citou que, embora a ideia de plantios para restauração de ecossistemas seja relativamente recente, muitos dos primeiros plantios de árvores em grande escala foram realizados com objetivos referidos hoje como de "restauração" ou de "conservação". A restauração florestal pode ser necessária quando ecossistemas são perturbados por forças naturais ou antrópicas. Os primeiros esforços de restauração ou reabilitação focaram, principalmente, a redução de impactos resultantes de perturbações fora de áreas a serem restauradas, tais como carreamento aos cursos d'água de sedimentos provenientes de ecossistemas severamente perturbados. Programas mais recentes de restauração incluem ecossistemas nos quais apenas alguns dos componentes foram perdidos ou alguns dos processos tenham sido impactados.

Considerando-se a hipótese de que através da análise dos componentes da paisagem é possível locar as áreas de alta prioridade à restauração florestal, o estudo teve por objetivo avaliar o emprego da Avaliação Multicritérios em ambiente SIG, especificamente por meio do método Combinação Linear Ponderada, para agregar os fatores (proximidade da rede hidrográfica, proximidade da cobertura florestal, declividade, erodibilidade do solo e as restrições) na geração de mapa de área prioritária à restauração florestal, na parte inicial da bacia do rio Pardo, SP, visando à conservação de recursos hídricos.

\section{MATERIAL E MÉTODOS}

\section{Caracterização da área de estudo}

A sub-bacia do rio Pardo localiza-se na região centro sul do estado de São Paulo, abrangendo áreas dos municípios de Botucatu e Pardinho (Figura 1). A nascente do rio Pardo, seu principal curso de água, está localizada no município de Pardinho. A área estudada tem início na nascente do rio Pardo até o local de captação da SABESP, no município de Botucatu, estado de São Paulo, Brasil.

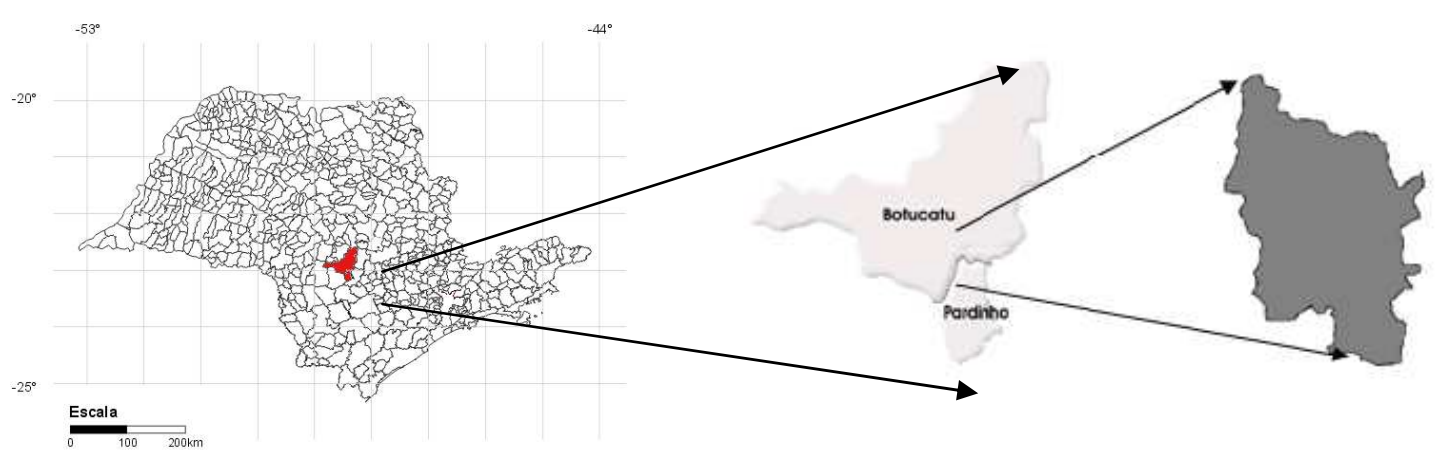

Figura 1. Localização da área de estudo sub-bacia do rio Pardo-SP.

Figure 1. Location of the studied area of River Pardo Basin, SP.

A sub-bacia possui uma área de $148,76 \mathrm{~km}^{2}$, sendo que o rio Pardo, seu principal curso de água, percorre um trecho de aproximadamente $28,7 \mathrm{~km}$ desde a sua nascente até o ponto de captação de água pela SABESP. O rio Pardo é afluente direito do rio Paranapanema, que por sua vez integra a bacia hidrográfica do rio Paraná.

A sub-bacia do Rio Pardo está geograficamente localizada entre as coordenadas $23^{\circ} 06^{\prime} 14^{\prime \prime}$ e $22^{\circ} 56^{\prime} 07^{\prime \prime}$ de latitude sul e $48^{\circ} 28^{\prime} 37^{\prime \prime}$ e $48^{\circ} 20^{\prime} 40^{\prime \prime}$ de longitude oeste de Greenwich, com altitudes variando entre 840 e $1.000 \mathrm{~m}$, de acordo com o Instituto Brasileiro de Geografia e Estatística (IBGE, 1969; IBGE, 1982). 
Com relação ao clima, a região pode ser enquadrada como tendo um clima mesotérmico, com estação mais seca no inverno e identificada como Cwa, segundo a classificação de Köppen, com temperaturas médias anuais torno de $20^{\circ} \mathrm{C}$ e índice pluviométrico entre 1.100 e $1.700 \mathrm{~mm}$ anuais (CARVALHO; JIM, 1983).

Do ponto de vista da vegetação, a biodiversidade é expressiva. Estão presentes matas de transição e atlântica, vegetação de cerrado e campo cerrado, contando ainda, segundo Tornero (1996), com "espécies isoladas do pinheiro-do-paraná (Araucaria brasiliensis), testemunho de um clima pretérito mais frio".

Ainda em termos ambientais, deve-se destacar a erosão que ocorre em algumas áreas em função das características naturais dos solos. Esse processo natural tem-se intensificado em razão de práticas inadequadas de uso e manejo do solo, acarretando, entre outros problemas, o depauperamento do solo e o assoreamento de rios e represas. Algumas áreas do município de Botucatu possuem alto grau de criticidade em relação à erosão. Grande parte da vegetação nativa foi suprimida para dar espaço às atividades agropecuárias e, em alguns casos, para o reflorestamento com espécies exóticas.

Tornero (1996), em estudo comparativo entre os anos de 1962 e 1977, confirma o aumento da área ocupada por lavouras anuais e reflorestamento, ao mesmo tempo em que se verifica uma redução da área ocupada por mata e mata ciliar na sub-bacia do rio Pardo. Além disso, a sub-bacia sofre também as consequências causadas pelo uso indiscriminado de agrotóxicos e despejo de esgotos domésticos, em geral, com pouco tratamento.

\section{Planos de informação}

Na elaboração dos planos de informação, utilizou-se o Datum SAD 69 e o Sistema de Projeção UTM, de acordo com as normas do Perfil Metadados Geoespaciais do Brasil, Comitê de Estruturação de Metadados Geoespaciais (CONCAR, 2009).

Para o mapeamento do uso e cobertura do solo, foram empregadas imagens orbitais obtidas pelo sensor HRC (High Resolution Camera ou Câmera Pancromática de Alta Resolução) a bordo do satélite CBERS 2B. Foram necessárias duas cenas para o recobrimento de toda a área da sub-bacia. Essas cenas são referentes à passagem do satélite no dia 12 de julho de 2008. Na tabela 1 podem ser observadas as características do modo de operação do sensor HRC a bordo do satélite CBERS 2B.

Tabela 1. Características do modo de operação do sensor HRC.

Table 1. Operating characteristics of the sensor HRC.

\begin{tabular}{lcccccc}
\hline Sensor & $\begin{array}{c}\text { Bandas } \\
\text { espectrais }\end{array}$ & $\begin{array}{c}\text { Resolução } \\
\text { espectral }\end{array}$ & $\begin{array}{c}\text { Resolução } \\
\text { espacial }\end{array}$ & $\begin{array}{c}\text { Resolução } \\
\text { temporal }\end{array}$ & $\begin{array}{c}\text { Res. } \\
\text { radiométrica }\end{array}$ & $\begin{array}{c}\text { Área } \\
\text { imageada }\end{array}$ \\
\hline HRC & PAN & $0,50-0,80 \mu \mathrm{m}$ & $2,7 \mathrm{~m}$ & 130 dias & 8 bits & 27 km (nadir) \\
\hline
\end{tabular}

O mapa de uso e cobertura do solo (Figura 2) foi produzido pelo processamento digital das imagens orbitais. Foi feita a correção geométrica utilizando-se o modelo de transformação polinomial de primeiro grau e o método de interpolação pelo vizinho mais próximo. Para essa correção, houve a identificação e o registro das coordenadas de pontos, denominados de controle, que foi comum entre as imagens digitais CBERS 2B e uma imagem do satélite LANDSAT-5 que, por sua vez, representou as coordenadas reais. As classes de uso e cobertura do solo foram definidas a partir do conhecimento de campo e pontos coletados com GPS.

A geração do plano de informação "fragmentos de floresta nativa" foi extraída do mapa de uso e cobertura do solo. Esses fragmentos foram individualizados, isto é, passaram a receber identificadores únicos.

O plano de informação "declividade do terreno" foi produzido a partir do modelo digital do terreno. Para elaboração desse modelo, foi utilizada a modelagem Triangulated Irregular Network (TIN), que é a estrutura mais comum utilizada para modelagem de superfícies contínuas usando dados vetoriais.

Através da triangulação, os valores das altitudes foram utilizados como vértices na geração de triângulos, resultando na triangulação da área da sub-bacia. Finalmente, foi gerado um modelo raster da superfície, em que os topos de morros e depressões são modelados de acordo com as tendências dos dados mais próximos.

A partir do modelo foi gerado o mapa de declividade, em porcentagem, que, posteriormente, foi reclassificado em sete categorias, conforme França (1963), a saber: 0-3\%; 3-6\%; 6-12\%; 12-20\%; 20$40 \%$; e acima de $40 \%$. 
A rede hidrográfica foi gerada pela digitalização em tela dos cursos d'água e represas, com auxílio de programa gráfico a partir das cartas topográficas do IBGE, na escala 1:50.000. A atualização da rede hidrográfica foi elaborada em tela dos cursos d'água de ordens menores e represas construídas após a edição dos mapas, tendo como base imagens do satélite CBERS 2B sensor HRC de resolução espacial 2,7 metros.

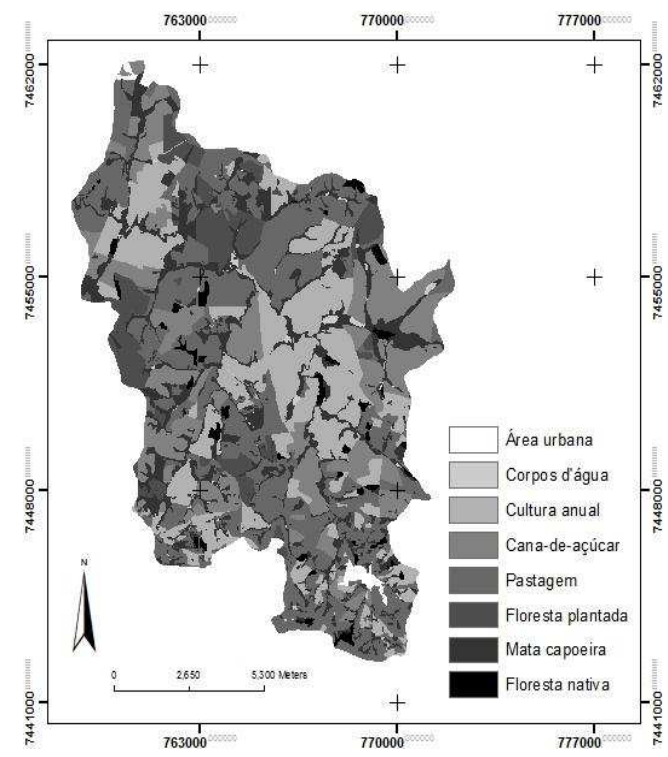

Figura 2. Cobertura do solo da sub-bacia do rio Pardo, SP.

Figure 2. Land cover of River Pardo Basin, SP.

O plano de informação referente aos solos da sub-bacia do rio Pardo (Figura 3) foi elaborado a partir da digitalização em tela do mapa do Levantamento Pedológico Semidetalhado da sub-bacia do rio Pardo, escala 1:10.000 Zimback (1997) adaptado por (GROSSI, 2003), reclassificados segundo normas da Empresa Brasileira de Pesquisa Agropecuária (EMBRAPA, 2006).

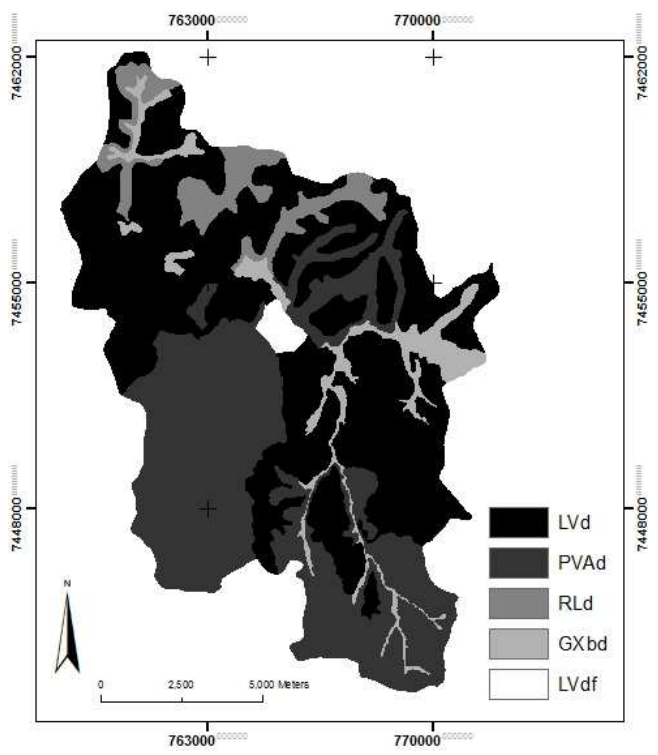

Figura 3. Classes de solo presentes na parte inicial da bacia do rio Pardo, SP. Figure 3. Soil classes present at the initial part of River Pardo Basin area, SP 
O plano de informação "erodibilidade do solo" foi obtido a partir da reclassificação do mapa de solos, sendo que cada classe de solo foi associada ao valor correspondente de erodibilidade. A erodibilidade do solo tem seu valor quantitativo determinado experimentalmente em parcelas unitárias, sendo expresso como a perda de solo por unidade de índice de erosão da chuva, tendo por unidade t.ha.h.ha ${ }^{-1} \cdot \mathrm{MJ}^{-1} \cdot \mathrm{mm}^{-1}$ (BERTONI; LOMBARDI NETO, 1985).

\section{Mapas de fatores}

Na definição dos critérios e restrições, empregou-se a Técnica Participativa proposta por Eastman (2001), Malczewski (1999), que se constitui na reunião e consulta de especialistas das diferentes áreas de interesse do trabalho.

Para aplicação dessa técnica, foi feita uma reunião no Grupo de Estudos e Pesquisas Agrárias Georreferenciadas (GEPAG) da Faculdade de Ciências Agronômicas (FCA/UNESP), que conta com vários integrantes de diversas formações, e consultados outros pesquisadores de diferentes áreas de conhecimento.

Dessa forma, todos os especialistas contribuíram com o trabalho, sugerindo fatores (características/atributos da paisagem) e explicando o motivo dessa escolha, que foram importantes aos objetivos.

Nessa reunião, foi apresentado o resumo inicial, sem os fatores previamente escolhidos, e uma tabela a ser preenchida com os fatores considerados e pesos (escala de 1 a 10) que foram atribuídos a cada um desses fatores.

Ao final do processo de revisão de literatura, da avaliação de projetos desenvolvidos e da Técnica Participatória, foram eleitos os fatores:

Proximidade da rede hidrográfica - Para elaboração desse mapa de fator, produziu-se o mapa de distância aos corpos d'água, a partir do plano de informação rede hidrográfica. Este, associado aos limites da bacia, possibilitou obter as distâncias somente dentro dos limites da bacia do rio Pardo. O mapa final foi normalizado (escala 0-255 bytes) com uma função linear decrescente. Desse modo, obtiveram-se os valores iguais e/ou próximos a 255 bytes da rede hidrográfica, em que os valores máximos são os de maior prioridade. Os rios e suas matas ciliares são elementos de extrema importância para a manutenção da biodiversidade, formando corredores ecológicos que, somados, compõem uma grande rede que integra toda a bacia hidrográfica e também diferentes ecossistemas.

Proximidade da cobertura florestal - Com esse mapa de fator, foram priorizadas as uniões entre os fragmentos de floresta (floresta nativa e mata capoeira), independentemente de seus tamanhos. A partir do plano de informação fragmentos de floresta, gerou-se um mapa com distâncias entre os fragmentos. Esse mapa foi associado ao limite da bacia e, em seguida, foi normalizado (escala 0 a 255 bytes) com uma função linear decrescente. Assim, ficou garantido que quanto mais próximo à cobertura florestal maior a importância (prioridade) da distância, sendo que os maiores valores (ex.: 255 bytes) estão associados aos fragmentos de floresta nativa. Considerou-se que áreas próximas à vegetação nativa são mais adequadas à recomposição, pelo fato de aumentar a continuidade da vegetação natural, aumentando assim as possibilidades de troca genética e a área contínua disponível para os movimentos da fauna local.

Declividade - Para elaboração desse mapa de fator, utilizou-se o plano de informação classes de declividade, em porcentagem. Considerou-se que áreas mais declivosas são mais adequadas à recomposição, devido à necessidade de proteção permanente do solo e à dificuldade de mecanização dessas áreas para o processo produtivo. Sendo assim, a imagem desse fator foi normalizada (0-255 bytes) de maneira a ter maior prioridade para os maiores valores de declividade. Dentro de uma paisagem, o relevo pode, portanto, ter uma influência decisiva na colonização vegetal, devido ao papel que ele tem em diversos fatores ecológicos. Inclinações maiores das encostas significam maior escoamento de água e, portanto, menor disponibilidade hídrica.

Erodibilidade do solo - O mapa do fator foi obtido a partir da reclassificação do mapa de solos, sendo que cada classe de solo foi associada ao valor correspondente de erodibilidade. Assim, a imagem desse fator foi padronizada ( 0 a 255 bytes) através de uma função linear crescente. Desse modo, obteve valores iguais e/ou próximos a 255 bytes a classe de solo de maior erodibilidade. Propriedades físicas (estrutura, textura, permeabilidade e densidade) e químicas dos diferentes tipos de solos geram efeitos distintos no 
processo de erosão. Essas propriedades causam maior ou menor resistência à ação da água mesmo em condições semelhantes de chuva, topografia e cobertura vegetal (BERTONI; LOMBARDI NETO, 1985).

Foram consideradas como áreas restritivas para o propósito deste trabalho as áreas de floresta nativa, corpos d'água e as áreas urbanas. Isso significa que o mapa final de áreas prioritárias considerou apenas o território dentro dos limites da bacia, exceto as áreas ocupadas por áreas de floresta nativa, corpos d'água e áreas urbanas.

Para calcular o peso para cada fator, foi utilizado o processo de tomada de decisão, conhecido como Análise Hierárquica Analítica (SAATY, 1977). Esse método emprega uma comparação pareada entre fatores para determinar a importância relativa de cada um deles. Os valores são derivados de uma escala contínua de nove pontos (Tabela 2).

Tabela 2. Escala contínua de nove pontos usada na comparação pareada entre fatores, na Avaliação Multicritérios. Fonte: Eastman (2001).

Table 2. Continuous scale of nine points used in the pairwise comparison between factors in Multicriteria Evaluation. Source: Eastman (2001).

\begin{tabular}{lcccccccc}
\hline $\mathbf{1 / 9}$ & $\mathbf{1 / 7}$ & $\mathbf{1 / 5}$ & $\mathbf{1 / 3}$ & $\mathbf{1}$ & $\mathbf{3}$ & $\mathbf{5}$ & $\mathbf{7}$ & $\mathbf{9}$ \\
$\begin{array}{l}\text { Extrema- } \\
\text { mente }\end{array}$ & $\begin{array}{c}\text { Muito } \\
\text { fortemente }\end{array}$ & $\begin{array}{c}\text { Forte- } \\
\text { mente }\end{array}$ & $\begin{array}{c}\text { Moderada- } \\
\text { mente }\end{array}$ & $\begin{array}{c}\text { Igual- } \\
\text { mente }\end{array}$ & $\begin{array}{c}\text { Moderada- } \\
\text { mente }\end{array}$ & $\begin{array}{c}\text { Forte- } \\
\text { mente }\end{array}$ & $\begin{array}{c}\text { Muito } \\
\text { fortemente }\end{array}$ & $\begin{array}{c}\text { Extrema- } \\
\text { mente }\end{array}$ \\
\hline
\end{tabular}

$\mathrm{Na}$ atribuição de pesos, um indivíduo, ou grupo, compara todos os possíveis pares e entra com os valores em uma matriz de comparação pareada. Uma vez que a matriz é simétrica, somente a metade triangular inferior necessita ser preenchida (Tabela 3).

Tabela 3. Pesos de compensação obtidos através da matriz de comparação pareada.

Table 3. Balancing weights obtained by pairwise comparison matrix.

\begin{tabular}{lccccc}
\hline & Fator 1 & Fator 2 & Fator 3 & Fator 4 & Pesos \\
\hline Fator 1 & 1 & & & & 0,0955 \\
Fator 2 & 1 & 1 & & & 0,0955 \\
Fator 3 & 3 & 3 & 1 & & 0,2495 \\
Fator 4 & 5 & 5 & 3 & 1 & 0,5596 \\
\hline
\end{tabular}

Taxa de consistência (TC): 0,02. Fator 1: Erodibilidade do solo; Fator 2: Declividade; Fator 3: Proximidade da cobertura florestal; Fator 4: Proximidade da rede hidrográfica.

Os pesos calculados através da matriz de comparação pareada para os fatores erodibilidade do solo, declividade, proximidade da cobertura florestal e proximidade da rede hidrográfica foram 0,0955 , $0,0955,0,2495$ e 0,5596 , respectivamente.

Devido ao fato de a matriz de comparação pareada apresentar múltiplos caminhos (ou maneiras) pelos quais a importância relativa dos critérios pode ser avaliada, é possível também determinar o grau de consistência atingido no desenvolvimento dos pesos. Saaty (1977) indicou o procedimento pelo qual um índice de consistência conhecido como Taxa de Consistência (TC) pode ser obtido. A TC indica a probabilidade de os valores da matriz terem sido gerados ao acaso (ou randomicamente). De acordo com $\mathrm{o}$ autor, as matrizes com TC maiores que 0,10 devem ser reavaliadas.

A TC dos pesos encontrada para este estudo foi de 0,02 , indicando que o julgamento apresentou consistência aceitável, ou seja, menor que $0,1(10 \%)$. Essa ponderação tem influência direta sobre a espacialização das áreas prioritárias à restauração florestal a serem geradas pela análise.

Um dos métodos mais empregados na AMC é a Combinação Linear Ponderada (CLP) (VOOGD, 1983). Uma vez que os mapas de critérios (fatores e restrições) tenham sido gerados, é uma simples questão de multiplicar cada mapa de fator (isto é, cada célula, ou pixel, de cada mapa) pelo seu peso e então somar os resultados. Devido aos pesos terem de somar 1, o mapa de adequação resultante terá uma variação de valores como aqueles dos mapas de fatores padronizados que foram usados. Após todos os fatores terem sido incorporados, o mapa de adequação resultante é então multiplicado por cada uma das restrições, para eliminar as áreas não adequadas. 


\section{RESULTADOS E DISCUSSÃO}

Na figura 4 observa-se o mapa de áreas prioritárias à restauração florestal na sub-bacia do rio Pardo, SP, gerado através da análise integrada dos dados disponíveis sobre a área em estudo, segundo os critérios e pesos estabelecidos pela Técnica Participatória. Pode-se observar que o mapa não identificou as áreas aptas ou inaptas à restauração florestal, mas representou uma superfície de aptidão em que todos os pixels possuem uma nota de 0 byte (menos apto à restauração florestal) a 255 bytes (mais apto à restauração florestal), resultante da aplicação dos critérios e da análise ponderada.

A partir dessa superfície, foi possível estabelecer um limiar para a seleção das melhores áreas, ou efetuar uma hierarquização das células (pixel), de forma a selecionar apenas as melhores áreas para a restauração florestal e nestas isolar uma ou mais áreas contíguas. Dessa forma, o mapa permitiu uma visão geral de como a paisagem da bacia se comporta em termos de aptidão à implantação de uma estratégia de restauração. Isso gerou a possibilidade de escolha dos locais dentro das áreas mais aptas e que merecem um estudo mais detalhado.

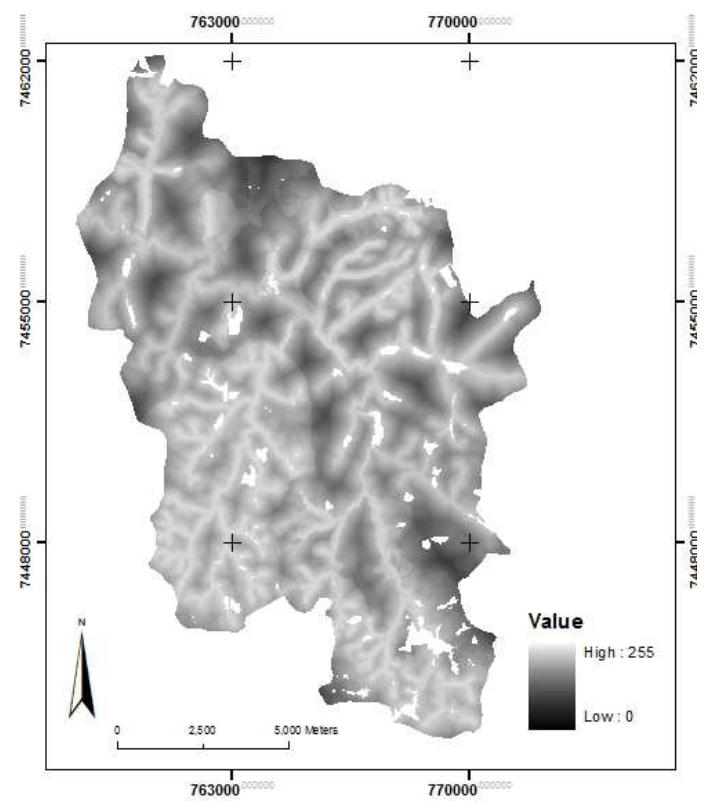

Figura 4. Mapa de áreas prioritárias à restauração na parte inicial da bacia do rio Pardo.

Figure 4. Map of priority areas for restoration at Pardo River Basin.

O mapa final de áreas prioritárias reclassificado (Figura 5) facilitou avaliar a relação das áreas prioritárias à restauração florestal na parte inicial da bacia do rio Pardo, SP, visando à conservação dos recursos hídricos, além de tornar mais fácil a interpretação do mapa. Foram definidas para o mapa de áreas prioritárias à restauração florestal cinco classes de prioridade (classes de mesma amplitude): muito baixa, baixa, média, alta e muito alta. $\mathrm{O}$ intervalo de classe foi determinado a partir da avaliação do histograma dos mapas ( $0-255$ bytes).

Pela Combinação Linear Ponderada, as áreas de prioridade muito alta apresentam uma distribuição espacial mais restrita, com uma concentração aparente ao redor dos corpos d'água, delineando uma área-tampão (buffer) para a rede hidrográfica. A distribuição espacial dessas áreas, próximas às cabeceiras e aos cursos d'água de ordens inferiores, é de grande importância para restauração florestal (BURKAT et al., 2004).

A análise visual do mapa com os cinco níveis categóricos de prioridade já possibilita uma primeira inferência sobre sua adequação. Pode-se observar no mapa (Figura 5) que os valores de área são crescentes até o nível alto, decrescendo no muito alto, com uma concentração no nível alto + muito alto $(77,51 \%)$, como pode ser observado na tabela 4. 


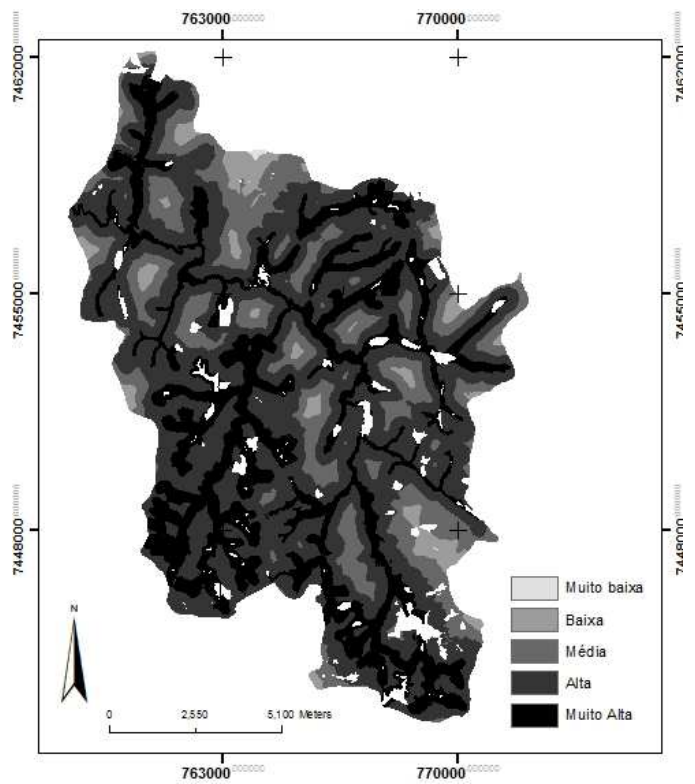

Figura 5. Mapa de áreas prioritárias à restauração florestal (cinco níveis de prioridade).

Figure 5. Map of priority areas for restoration (five levels of priority).

Tabela 4. Valores de área para os cinco níveis de prioridade.

Table 4. Area values for the five priority levels.

\begin{tabular}{lcc}
\hline \multirow{2}{*}{ Nível de prioridade } & \multicolumn{2}{c}{ Área } \\
\cline { 2 - 3 } & $\mathbf{( h a )}$ & $\mathbf{( \% )}$ \\
\hline Muito baixo & 12,08 & 0,08 \\
Baixo & 569,20 & 3,82 \\
Médio & $2.763,97$ & 18,57 \\
Alto & $7.362,29$ & 49,47 \\
Muito alto & $4.174,10$ & 28,04 \\
\hline Total & $14.881,64$ & 100,00 \\
\hline
\end{tabular}

Deve-se ressaltar que o valor da área total da bacia (Tabela 4) refere-se à área total passível de restauração, isto é, aplicadas as devidas restrições.

No mapa gerado pela Combinação Linear Ponderada, especificamente para as áreas classificadas como de prioridade alta e muito alta, pode-se perceber nitidamente a influência dos fatores proximidade da rede hidrográfica e proximidade da cobertura florestal na espacialização dessas áreas, porque são fatores com os maiores pesos (Tabela 2). O fator proximidade da rede hidrográfica, além de possibilitar a conexão florestal, colaborou, juntamente com o fator proximidade da cobertura florestal, para que houvesse a definição de grande parte das áreas com maior prioridade em regiões da bacia, que concentram as maiores áreas de floresta nativa e áreas ripárias ao longo da hidrografia.

Burkat et al. (2004) comentou que as áreas ripárias ao longo dos canais de primeira ordem têm um potencial maior de interceptação da água, subterrânea ou superficial, que áreas similares ao longo de canais de ordens superiores, contribuindo dessa forma para recarga desses cursos pequenos, que é dominado pelo fluxo de base. Lima (2005) também comenta a importância da proteção adequada das zonas ripárias e das cabeceiras de drenagem, para garantir a integridade do sistema ripário, contribuindo, dessa forma, para aumentar a resiliência da bacia hidrográfica, diminuindo a sua vulnerabilidade a perturbações. 


\section{CONCLUSÕES}

- A Avaliação Multicritérios mostrou-se adequada ao mapeamento de áreas prioritárias à restauração florestal em bacias hidrográficas, visando à conservação dos recursos hídricos. Com o auxílio das rotinas de apoio à decisão do software, pôde-se verificar de modo mais objetivo que as áreas destinadas à recomposição florestal da sub-bacia do rio Pardo-SP devem ter prioridade em planejamento e/ou execução de uma intervenção pública. Tanto os dados básicos quanto o resultado da análise constituem importante subsídio para o zoneamento e para a elaboração de um plano de manejo para a área a ser restaurada.

- O método da Combinação Linear Ponderada apresenta a vantagem de contemplar o rigor matemático da análise, mas de outro lado oferece ao leitor leigo a possibilidade de visualizar os resultados intermediários e o final de forma simples. Adicionalmente, permite aproveitar a experiência de determinadas pessoas e incorporá-la na análise, mesmo que essa variável não seja quantificável.

- Deve-se ressaltar, no entanto, que é importante primeiramente definir os critérios a partir dos quais os fatores e as restrições serão gerados. A partir deles o uso dos módulos de apoio à decisão presentes no software permite a geração rápida de outros cenários, baseados na definição de pesos diferentes a cada um dos fatores.

- Dessa forma, considera-se a utilização das ferramentas de apoio à decisão imprescindível ao planejamento ambiental. O geoprocessamento pode ser útil na preservação de áreas verdes, propiciando maior eficiência, flexibilidade e grau de complexidade no tratamento dos dados, com inúmeras aplicações em nível gerencial, operacional e estratégico.

\section{REFERENCIAS}

BERTONI, J.; LOMBARDI NETO, F. Conservação do solo. Piracicaba: Livroceres, 1985. 368 p.

BURKAT, M. R.; JAMES, D. E.; TOMER, M. D. Hydrologic and terrain variables to aid strategic location of riparian buffers. Journal of Soil and Water Conservation, Ankeny, v. 59, p. 216 - 223, 2004.

CALIJURI, M. L.; ALVES, J. E. M.; BAPTISTA, A. C.; SANTIAGO, A. F.; LOURES, S. S. P. Proposta metodológica para geração da carta de fragilidade ambiental, utilizando lógica Fuzzy e Combinação Linear Ponderada. Anais XIII Simpósio Brasileiro de Sensoriamento Remoto, Florianópolis, Brasil, 2126 abril 2007, INPE, p. 3311 - 3318.

CARVALHO, W. A.; JIM, J. Áreas de proteção ambiental: Região da "Serra de Botucatu" e Região da "Serra de Fartura". Botucatu: Instituto Básico de Biologia, Faculdade de Ciências Agronômicas, Universidade Estadual Paulista, 1983. 47 p.

CHAKHAR, S.; MARTEL, J. M. Enhancing geographical information systems capabilities with multicriteria evaluation functions. Journal of Geographic Information and Decision Analysis, v. 7, p. 47 71. 2003.

COMitÊ DE ESTRUTURAÇÃo DE METADADOS GEOESPACIAIS (CEMG-CONCAR). Perfil de Metadados Geoespaciais do Brasil. 2009.

COWEN, D. GIS versus CAD versus DBMS: what are the differences? Photogrammetric Enginnering and Remote Sensing. v. 54, n. 11, p. 1511 - 1555. 1988.

DONHA, A. G.; SOUZA, L. C. P.; SUGAMOSTO, M. L. Determinação da fragilidade ambiental utilizando técnicas de suporte à decisão e SIG. Revista Brasileira de Engenharia Agrícola e Ambiental, v. 10, n. 1, p. 175 - 181, 2006.

EASTMAN, J. R. Decision support: decision strategy analysis. In: Idris 32 release 2: guide to GIS and image processing. Worcester: Clark University, Clark Labs, 2001. v. 2, p. 1 - 22.

EMPRESA BRASILEIRA DE PESQUISA AGROPECUÁRIA (EMBRAPA). Serviço Nacional de Levantamento e Conservação de Solos: Manual de Métodos de Análise de Solo. Rio de Janeiro, 2006. 212 p. 
FRANÇA, G. V. A classificação de terras de acordo com sua capacidade de uso como base para um programa de conservação de solo. In: CONGRESSO NACIONAL DE CONSERVAÇÃO DO SOLO, 1, 1963. Campinas. Anais... São Paulo: Secretária da Agricultura, Divisão Estadual de Máquinas Agrícolas, 1963. p. 399 - 408.

GROSSI, C. H. Sistema e Informação Geográfica - Basins 3.0 na Modelagem hidrológica da Bacia Experimental do rio Pardo, SP. Dissertação (Mestrado em Agronomia) - Faculdade de Ciências Agronômicas, Universidade Estadual Paulista, 2003.

HARRINGTON, C. A. Forests planted for ecosystem restoration or conservation. New Forests, Dordrecht, v. 17, n. 1/3, p. 175 - 190, 1999.

INSTITUTO BRASILEIRO DE GEOGRAFIA E ESTATÍSTICA (IBGE). Carta do Brasil. Mapa color, 55,3x51,4 cm (folha SF - 22 - R - W - IV - 3 Botucatu). Escala 1:50.000, 1969.

.Carta do Brasil. Mapa color, 55,3x51,4cm (folha SF - 22 - Z - D - III - 1 Pardinho). Escala 1:50.000, 1982.

LIMA, W. P. Floresta natural protege e estabiliza recursos hídricos. Visão Agrícola, Piracicaba, ano 2, n. 4 , p. $30-33,2005$.

MALCZEWSKI, J. GIS and multicriteria decision analsis. New York: John Wiley, 1999. 362 p.

GIS-based land-use suitability analysis: a critical overview. Progress in Planning, New York, n. 62 , p. $3-65,2004$.

GIS-based multicriteria decision analysis: a survey of the literature. International Journal of Geographical Information Science, v. 20, n. 7, 2006, p. 703 - 726.

RIBEIRO, G. F. Estudo dos fatores do meio físico que influenciam a capacidade de infiltração das águas da bacia hidrográfica Vargens de Caldas, Minas Gerais. Dissertação (Mestrado) - Universidade Estadual de Campinas, 2010.

SAATY, L. L. A scaling method for priorities in hierarchical structures. Journal of Mathematical Psychology, San Diego, v. 15, p. 234 - 281, 1977.

SARTORI, A. A. C. Análise multicritérios na definição de áreas prioritárias à conectividade entre fragmentos florestais. Dissertação (Mestrado) - Universidade Estadual Paulista, Faculdade de Ciências Agronômicas de Botucatu, 2010.

TORNERO, M. T. Fotointerpretação da cobertura vegetal e da rede de drenagem da Bacia Experimental do Rio Pardo, no período de 15 anos. Dissertação (Mestrado) - UNESP, Faculdade de Ciências Agronômicas, Botucatu, 1996. 129 p.

VALENTE, R. O. A. Definição de áreas prioritárias para conservação e preservação florestal por meio da abordagem multicriterial em ambiente SIG. Tese (Doutorado) - Escola Superior de Agricultura "Luiz de Queiroz" USP, 2005. Piracicaba. 121 p.

VETTORAZZI, C. A. Avaliação multicritérios, em ambiente SIG, na definição de áreas prioritárias à restauração florestal visando à conserva de recursos hídricos. Tese (Livre Docência) - Escola Superior de Agricultura "Luiz de Queiroz" USP, 2006. Piracicaba. 151 p.

VOOGD, H. Multicriteria evaluation for urban and regional planning. London: Pion, 1983. 370 p.

ZHU, X.; DALE, A. P. Java AHP: A Web-based decision analysis tool for natural resource and environmental management. Environmental Modelling and Software, v. 16, n. 3, p. 251 - 262, 2001.

ZIMBACK, C. R. L. Levantamento semidetalhado dos solos da bacia do rio Pardo nos municípios de Pardinho e Botucatu. Botucatu: Faculdade de Ciências Agronômicas, Universidade Estadual Paulista, 1997. $55 \mathrm{p}$. 
